\title{
IDENTIFIKASI DAN PEMBERDAYAAN MASYARAKAT MISKIN NELAYAN TRADISIONAL
}

\author{
Abdul Ahmad Ali \\ Program Studi Perencanaan Wilayah dan Kota Fakutas Teknik Universitas Islam Sultan Agung \\ Email korespondesi : ahmadcluwak@gmail.com
}

\begin{abstract}
As a maritime country, Indonesia is surrounded by very wide waters. This abundant potential is exploited by people who earn their living as traditional fishermen. However, their existence is defeated by modern fishermen so that traditional fishermen are still in a poverty-environment so that empowerment efforts are needed to improve the welfare of traditional fishermen. The method used in the qualitative literature study. From the results of the discussion, it can be seen that the poverty-stricken poverty there has a limited education, limited marine resources, and intensive competition. This poverty has an impact on their slum environment. The empowerment strategy implemented includes strengthening human resources through training, providing more sophisticated capital and technology, and ordering local fishermen organizations to function as a forum for discussion, helping each other solve problems.
\end{abstract}

Keywords: traditional fishermen, poverty, empowerment.

\begin{abstract}
Abstrak
Sebagai negara maritim Indonesia di kelilingi oleh perairan yang sangat luas. Potensi yang melimpah dimanfaatkan masyarakat yang bermata pencaharian sebagai nelayan tradisonal. Namun, keberadaan mereka dikalahkan oleh nelayan modern sehingga nelayan tradisional masih berada pada lingkar kemiskinan sehingga perlu adanya upaya pemberdayaan untuk meningkatkan kesejahteraan nelayan teradisional. Metode yang digunakan dalam kualitatif studi literatur. Dari hasil pembahasan dapat disimpulkan bahwa penyebab kemiskinan di antaranya adanya keterbatasan di bidang pendidikan, minimnya teknologi, keterbatasan akses modal, terbatasnya potensi sumberdaya laut, dan persaingan yang intensif. Kemiskinan tersebut berdampak terhadap kondisi lingkungan mereka yang kumuh. Strategi pemberdayaan yang diterapkan di antaranya dengan menguatkan sumberdaya manusia melalui pelatihan, memberikan modal dan teknologi yang lebih canggih, serta pembentukan organisasi nelayan lokal yang berfungsi sebagai wadah berdiskusi, saling membantu menyelesaikan masalah.
\end{abstract}

Kata kunci : Nelayan tradisional, Kemiskinan, Pemberdayaan. 


\section{PENDAHULUAN}

Indonesia adalah negara kepulauan yang tiga perempat dari luas wilayahnya merupakan lautan. Di lautan terdapat sumberdaya ikan yang melimpah. Melimpahnya sumberdaya ikan seharusnya kehidupan nelayan bisa sejahtera. Tetapi dalam kenyataannya tidaklah demikian, kemiskinan masih banyak menyelimuti kehidupan nelayan (Arifianto, $\mathrm{S}$ dan Udi, 2013). Di Indonesia terdapat nelayan miskin sejumlah 7,87 juta orang, atau $25,14 \%$ dari penduduk miskin Nasional yang berjumlah 31,02 juta orang. Angka tersebut bersumber dari 10.600 desa nelayan miskin di sepanjang pesisir pantai Indonesia (Retnowati, 2011). Banyaknya nelayan miskin tidak sebanding dengan besarnya potensi perikanan di Indonsia. Jika potensi tersebut dapat di manfaatkan dengan baik maka tidak menutup kemungkinan kemiskinan nelayan akan berkurang.

Di Indonesia terdapat nelayan tradisional dan nelayan modern. Nelayan tradisional memiliki ciri-ciri dengan perlatan yang minim, modal usaha yang terbatas, dan organisasi penangkapan yang kecil. Nelayan tradisional memilki hasil yang hanya cukup untuk kebutuhan hidup sehari-hari tanpa mampu untuk ditabungkan untuk usaha dalam skala yang lebih besar. Sedangkan nelayan modern bisa menghadapi perubahan sehingga lebih banyak tangkapan hasilnya. Perbandingan mereka sangat jelas pada keterbatasan penguasaan teknologi, ruang gerak berupa bagian pantai serta tengah lautan.

Persaingan nelayan tradisional dan modern dimenangkan nelayan modern karena alat yang digunakan lebih memumpuni sehingga mendapatkan hasil yang lebih besar. Akibanya nelayan tradisional masih dalam lingkar kemiskinan.

Kehidupan nelayan tradisional ditandai dengan rendahnya tingkat sosial dan /ekonomi. Kemiskinan yang dialami nelayan bersumber dari faktor alamiah dan nonlamiah. Fakor alamiah yaitu fluktasi musim penangkapan dan struktur alamiah sumberdaya ekonomi. Sedangkan faktor non-alamiah, yaitu keterbatasan alat, ketidakrataan bagi hasil, dan tidak ada jaminan sosial tenaga kerja secara pasti, lemahnya penguasaan jaringan pemasaran dan belum berfungsinya lembaga koperasi nelayan serta akibat kebijakan modernisasi perikanan yang merugikan (Hidayat, 2018).

Dampak kemiskinan terhadap nelayan di antaranya keterbatatasan dalam ilmu pengetahuan, kurangnya sarana teknologi, dan terbatasnya modal. Faktor lainnya yaitu keterbatasan dalam mengelola sumber daya yang bisa digunakan, perebutan dengan pelaku usaha dengan modal yang lebih besar, rendahnya nilai tawar oleh tengkulak, dan kondisi sarana pelabuhan. 
Untuk memperbaiki kondisi kehidupan nelayan tersebut diperlukan adanya pemberdayaan masyarakat yang membentuk seseorang lebih mandiri. Pemberdayaan yang diterapkan harus bisa menjawab permasalahan masyarakat nelayan yaang dialami selama ini. Dengan adanya pendekatan pembangunan yang berpusat pada masyarakat diharapkan dapat meningkatkan kesejahteraan masyarakat nelayan (Hariyanto, 2014). Dengan adanya kesejahteraan masyarakat nelayan nantinya juga bisa mengubah kondisi lingkungan mereka menjadi lebih bersih dan sehat.

Berdasarkan permasalahan tersebut, tujuan dilakukan penelitian ini adalah untuk mengidentifikasi dan melakukan analisis terkait strategi pemberdayaan masyarakat miskin nelayan tradisional berdasarkan teori serta studi kasus yang pernah dikaji sebelumnya.

\section{KAJIAN TEORI}

\section{a. Masyarakat Nelayan}

Masyarakat nelayan adalah masyarakat yang hidup di wilayah pesisir. Masyarakat yang tinggal disini memiliki kehidupan sosial serta kebudaayang yang yang berbeda dengan nelayan lainnya yang berpengaruh pada perilaku kehidupan mereka (Kadriani \& Harudu, 2017).

\section{b. Kemiskinan Masyarakat Nelayan Tradisional}

Nelayan tradisonal di Indonesia masih tergolong miskin. Indonesia yang adalah negara maritim yang kelilingi oleh lautan yang sangat dan memiliki potensi sumberdaya laut yang melimpah. Potensi tersebut bisa menjadi penopang perekonomian bagi masyarakat yang bekerja sebagai nelayan. Perubahan sosial dan ekonomi yang semakin berkembang mmebuat masyarakat yang bekerja sebagai nelayan tradisional mendapatkan dampaknya. Para pelaku usaha yang memiliki modal yang tinggi lebih berkuasa sehingga nelayan tradisional hanya mendapatkan keuntungan yang sedikit (Goso \& Anwar, 2017)

\section{c. Konsep Pemberdayaan Masyarakat}

Menurut Gai (2020) upaya yang dapat dilakukan untuk melakukan pemberdayaan terhadap masyarakat nelayan dengan konsep pendekata kehidupan berkelanjutan. Kosep ini digunakan dengan mencakup semua aspek penting dalam kehidupan sehari-hari seperti aspek sosial,ekonomi dan lingkungan. Konsep yang bisa digunakan antara lain:

\section{Konsep Sosial}


Konsep ini difokuskan untuk menumbuhan kepercayaan diri antar para nelayan dalam keluarga besar nelayan. Selain itu, untuk menumbuhkan komunikasi antar sesama nelayan. Hal ini dapat dilakukan dengan sosialasi secara rutin dan bertahap.

2. Konsep lingkungan

Konsep ini bertujuan untuk memberi pengetahuan tentang kondisi alam seperti perubahan ilkim sehingga bisa menjadi acuan ketika ingin melaut. Konsep ini dapat dilakukan dengan pengenalan teknologi yang bisa dimaanfaatkan oleh para nelayan.

\section{Konsep Fisik}

Konsep ini bertujuan untuk untuk memberi pengetahuan tentang pentingnya menjaga sarana dan fasilitas umum lainnya sebagai penunjang dalam kehidupan seha-hari seperti infrastruktur lingkungan sekitar. Hal yang dapat dilakukan antara lain dengan gotong royong memperbaiki jalan sebagai alat penghubung serta pembangunan tempat menjual ikan yang dapat menampung hasil tangkapan nelayan.

\section{d. Prinsip Pemberdayaan Masyarakat Nelayan}

Menurut Kandati, Mantiri, \& Moninjta (2019) prinsip yang dilakukan dalam upaya pemberdayaan masyarakat nelayan yaitu :

1. Pemberdayaan bersifat demokratis sehingga tidak memaksa pihak nelayan. Tiap nelayan memiliki kemampuan dan kebutuhan yang berbeda-beda sehingga pemberdayaan dilaksanakan sesuai kebutuhan.

2. Dalam pelaksanaannya difokuskan untuk membangun kesadaran masayarakat nelayan sehingga memudahkan dalam pengembangan potensi yang dimiliki.

3. Memadukan konsep dengan budaya lokal contohnya gotong royong sebagai bentuk upaya pemberdayaan sosial.

4. Dilakukan secara bertahap dan berkelanjutan agar mempunyai hasil yang maksimal.

5. Kesabaran menjadi kunci penting dalam pelaksaan pemberdayaan karena dihadapkan denganm masyarakat yang memiliki karakter dan pemikiran yang beragam. 
6. Pemberdayaan perlu dilaksanan dengan semua aspek yang dibutuhkan dalam kehidupan sehari-hari.

\section{e. Alasan Pemberdayaan Masyarakat Nelayan Tradisional}

Nelayan tradisonal merupakan pelaku usaha dengan modal yang kecil. Perlengkapan untuk menangkap ikan yang sederhana. Mereka bekerja sebagai nelayan untuk memenuhi kebutuhan sehari-hari. Sementara itu, nelayan modern dengan perlengkapan yang lebih memadai menguasai pasar perikanan Indonesia maupun kancah internasional. Persaingan akan dimenangkan para nelayan modern dan nelaya tradisional akan semakin tersingkirkan (Hidayat, 2017).

Nelayan tradisional masih menggunakan cara yang alami dalam menangkap ikan. Mereka memahami kondisi alam di laut sehingga menggunakan cara yang sesuai dengan kondisi lautan yang sering berubah-ubah. Dengan cara yang alami, dapat memanfaatkan potensi sumberdaya alam yang tersedia namun juga ikut menjaga tanpa merusak sumber sumberdaya alam tersebut. Nelayan tradisonal perlu dilestarikan dan perlu didukung dari pemerintah maupun masyarakat lainnya.

Kebijakan untuk melindungi nelayan tradisonal dengan memperhatikan bebarapa aspek antara lain lingkungan, sosial, maupun ekonomi. Lingkungan merupakan sumber pekerjaan mereka. Aspek sosial dengan memberi memberi mereka pembekalan serta pemberian modal. Aspek ekonomi untuk meningkatkan kesejahteraan masyarakat nelayan tradisional. Penangkapan ikan secara berlebihan akan berdampak pada hasil tangkapan nelayan tradisional. Maka dari itu, penting untuk mebuat kebijakan agar nelayan tradional tetap bisa bekerja untuk meningkatkan kesejahteraan (Z. Rahman, 2019)

\section{METODE PENELITIAN}

Metode yang digunakan adalah kualitatif denggan pendekatan studi literatur. Studi literatur metode dengan cara mencari jurnal atau buku sesuai dengan tema penelitian yang diambil (B. Rahman \& Selviyanti, 2018). Dalam penelitian ini studi literatur yang diambil berlokasi di Kota Tegal, Kabupaten Halmahera Utara, Kabupaten Deli Serdang, Kota Sibolga, Kabupaten Buton, dan Pantai Selatan Jawa 


\section{HASIL DAN PEMBAHASAN}

\section{A. Faktor Penyebab Kemiskinan Masyarakat Nelayan Tradisional}

Penyebab kemiskinan nelayan tradisional dibedakan menjadi dua faktor yakni faktor internal dan eksternal. Faktor internal di antaranya seperti adanya keterbatasan dibidang pendidikan, kurangnya sarana teknologi, dan keterbatasan modal yang dimiliki. Sedangkan, faktor eksternal seperti terbatasnya potensi sumber daya laut yang bisa dimanfaatkan nelayan, persaingan yang intensif, mekanisme pasar, posisi tawar nelayan yang dihadapi tengkulak, dan keadaan infrastruktur pelabuhan perikanan. Faktor-faktor tersebut tidak hanya berkaitan dengan perubahan cepat pada musim ikan, keterbatasan sumberdaya manusia, keterbatasan akses modal, dan kurangnya sumber daya manusia, tetapi juga karena moderenisasi cara penagkapan ikan yang mendorong terjadinya eksploitasi sumberdaya laut secara besar-besaran. Hal tersebut terus berlangsung sampai sekarang yang menyebabkan menurunnya tingkat pendapatan nelayan tradisional karena hasil tangkap yang berkurang (Hidayat, 2018).

\section{B. Dampak Kemiskinan Masyarakat Nelayan Tradisioanl}

Wilayah pesisir memiliki karakter penduduk yang tinggal disana berkerja sebagai nelayan yang masih terpinggirkan dari padangan pememerintah. Kondisi sosial ekonomi maupun lingkungan yang jauh dari layak. Pembangunan di wilayah pesisir seperti industri besar munggusur tempat sumber mata pencaharian nelayan. Akibatya, penghasilan nelayan tradisonal yang semakin menurun. Keterbatasan dalam segi modal maupun kemampuan membuat nelayan tradisional masih terpersngkpa dalam pelik lingkar kemiskinan (Dewi, Agustar, \& Mahdi, 2019).

Dampak kemiskinan yang dirasakan oleh nelayan tradisional berpengaruh pada lingkungan tempat mereka tinggal. Kualiatas lingkungan yang semakin memburuk karena tidak mampu memperbaiki dan menjaganya. Permukiman di wilayah pesisir yang terkesan kumuh disebabkan masyarakat tidak memiliki kemampuan untuk mengubahnya. Kehidupan yang hanya cukup untuk memenuhi kebutuhan sehari-hari membuat mereka mengabaikan kondisi lingkungan disekitar.

Permukiman di wilayah pesisir yang tidak layak huni karena bangunan konstruksi sederhana. Kondisi jalan yang rusak akibat sering tekena rob dan kuramg perawatan. Selain itu, penyumbatan saluran draisane menimbulkan polusi 
udara. Kebutuhan air bersih juga sulit untuk didapatkan sehingga masyarakat menggunakan air sumur. Dengan kondisi seperti inilah mereka tinggal. Perlunya perbaikan serta peningkatan kualitas lingungan bagi masyarakat di pesisir agar layak untuk ditinggali (Hodijah, 2018).

Kemiskinan juga menutut para nelayan tradisonal mencari pekerjaan tambahan untuk tetap memenuhi kebutuhan hidup. Tak jarang mereka mmbuka usaha dirumah seperti warung ataupun usaha lainnya. Selain itu, menjadi ojek oline yang kini masih peminat yang tinggi juga dimanfaatkan nelayan untuk mencari penghasilan tambahan. 


\section{Studi kasus}

\begin{tabular}{|c|c|c|c|}
\hline \multirow[t]{2}{*}{ No } & \multirow[t]{2}{*}{ Studi Kasus } & \multicolumn{2}{|c|}{$\begin{array}{c}\text { Identifikasi Dan Pemberdayaan Masyarakat Miskin } \\
\text { Nelayan Tradisional }\end{array}$} \\
\hline & & Kondisi Sosial Ekonomi & Cara Peml \\
\hline 1 & Kota Tegal & $\begin{array}{l}\text { Nelayan di Kabupaten Tegal saat air laut sangat asin } \\
\text { sehingga tidak melaut dan beralih mencari pekerjaan } \\
\text { lain atau melakukan perbaikan pada alat yang } \\
\text { digunakan untuk meangkap ikan. Guna mendapatkan } \\
\text { modal, nelayan mencari mitra dengan sistem pinjaman. } \\
\text { Dengan sistem yang berlaku, nelayan tidak dapat } \\
\text { mwmukan jalan untuk keluar dari lingkar kemiskinan } \\
\text { (Vibriyanti, 2014). }\end{array}$ & $\begin{array}{l}\text { Pemberian pelatihan untuk } \mathrm{n} \\
\text { pengetahuan nelayan seperti ca: } \\
\text { perahu tradisional, pengolahan } \\
\text { keuangan dalam organisasi nelaya } \\
\text { tersebut pendekatan terhadap kel } \\
\text { supaya program tersebut memilki } \\
\text { 2014). }\end{array}$ \\
\hline 2 & $\begin{array}{l}\text { Kecamatan Mesjid } \\
\text { Raya Aceh Besar } \\
\text { (Studi Kasus } \\
\text { Pemukiman Lamnga) }\end{array}$ & $\begin{array}{l}\text { Masyarakat nelayan di Permukiman Lamnga dari segi } \\
\text { pendidikan, kondisi rumah, pendapatan, kesehatan, dan } \\
\text { tanah secara umum tidak mampu mencukupi } \\
\text { kebutuhan hidup sehari-hari. Tanah sebagai aset } \\
\text { mereka tidak dapat dimanfaatkan secara optimal } \\
\text { karena kurang modal dan pengetahuan teknologi. } \\
\text { Permukiman Lamnga masih berada di garis } \\
\text { kemiskinan dikarenakan faktor pendidikan, modal, dan } \\
\text { pendapatan yang rendah (Riza et al., 2016). }\end{array}$ & $\begin{array}{l}\text { Pembuatan program khusus dalam } \\
\text { prasarana di sektor perikanan. Se } \\
\text { dan prasarana di sektor perika } \\
\text { Permukiman Lamnga memiliki } \mathrm{k} \\
\text { pencaharian nelayan. Modal unt } \\
\text { berpengaruh terhadap pendapatan }\end{array}$ \\
\hline 3 & $\begin{array}{l}\text { Desa Percut, } \\
\text { Kecamatan Percut } \\
\text { Sei Tuan, Kabupaten } \\
\text { Deli Serdang }\end{array}$ & $\begin{array}{l}\text { Nalayan di sana memiliki ketergantungan terhadap alat } \\
\text { produksi. Dari sepuluh nelayan hanya tiga orang } \\
\text { nelayan yang memiliki alat tangkap ikan sendiri. } \\
\text { Itupun merupakan alat yang sangat sederhana seperti } \\
\text { perahu, pancing, jaring, dan mesin yang kapasitasnya }\end{array}$ & $\begin{array}{l}\text { Pemberdayaan nelayan tradisional } \\
\text { ekonomi dilakukan dengan melak } \\
\text { terhadap kenaikan harga BBM per } \\
\text { pembuatan program ekonomi } \\
\text { keberlanjutan, dan pembentukar }\end{array}$ \\
\hline
\end{tabular}




\begin{tabular}{|c|c|c|c|}
\hline \multirow[t]{2}{*}{ No } & \multirow[t]{2}{*}{ Studi Kasus } & \multicolumn{2}{|c|}{$\begin{array}{c}\text { Identifikasi Dan Pemberdayaan Masyarakat Miskin } \\
\text { Nelayan Tradisional }\end{array}$} \\
\hline & & Kondisi Sosial Ekonomi & \begin{tabular}{|l|} 
Cara Pemberdayaan \\
\end{tabular} \\
\hline & & $\begin{array}{l}\text { rendah yakni di bawah } 30 \text { GT (gros ton). Selain itu } \\
\text { dalam mencukupi kebutuhan sehari-harinya nelayan } \\
\text { meminjam uaag kepada toke, pinjaman tersebut } \\
\text { dipotong dari hasil melautnya. Faktor laian yaitu } \\
\text { kurangnya kemampuan nelayan untuk mengekplorasi } \\
\text { sumber daya yang ada di laut dikarenakaan alat } \\
\text { tangkap ikan yang kurang canggih (Ginting, 2018). }\end{array}$ & $\begin{array}{l}\text { Kemudian pemberdayaan masyarakat mandiri kelautan dan } \\
\text { perikanan dilakukan dengan pengembangan usaha mina desa, } \\
\text { pemberdayaan usaha garam rakyat, dan pemberdayaan nelayan } \\
\text { terhadap kesiapan dampak akan kejadian bencana maupun } \\
\text { perubahan iklim (Ginting, 2018). }\end{array}$ \\
\hline 4 & $\begin{array}{l}\text { Kecamatan Waduk } \\
\text { Kabupaten Demak }\end{array}$ & $\begin{array}{l}\text { Pendapatan keluarga nelayan di Kecamatan Waduk } \\
\text { Kabupaten Demak berkurang karena hasil tangkap ikan } \\
\text { yang sedikit. Hal tersebut yang menjadi salah satu } \\
\text { faktor kemiskinan nelayan tradisional. Berkurang hasil } \\
\text { tangkap salah satunya dikarenakan kurangnya } \\
\text { pengetahuan teknologi. Informasi dan penerapan } \\
\text { teknologi baru merupakan sarana bagi nelayan untuk } \\
\text { meningkatkan pendapatan mereka (Santosa et al., } \\
\text { 2019). }\end{array}$ & $\begin{array}{l}\text { Pemberdayaan dilakukan dengan memberikan inovasi yang ramah } \\
\text { lingkungan dan produktif. Nelayan tradisional di sana diberikan } \\
\text { lampu listrik dalam air dengan tenaga surya. Dengan adanya lampu } \\
\text { tersebut bisa memberikan manfaat seperti peningkatan hasil } \\
\text { tangkapan dan hemat biaya operasional. Ikan-ikan akan lebih } \\
\text { banyak menghampiri dibanding tidak ada lamapu. Selain itu, } \\
\text { nelayan tidak bergantung bahan bakar minyak. Dengan adanya } \\
\text { inovasi tersebut bisa mengurangi kecemburuan sosial dengan } \\
\text { nelayan besar (Santosa et al., 2019). }\end{array}$ \\
\hline 5 & $\begin{array}{l}\text { Kabupaten Buton, } \\
\text { Sulawesi Tenggara }\end{array}$ & $\begin{array}{l}\text { Cuaca menjadi faktor dalam penentuan hasil tangkapan } \\
\text { nelayan tradisonal di Kabupaten Buton. Karena } \\
\text { pengahasilan yang tidak mennetu, masyarakat nelayan } \\
\text { tradisional banyak yang masih berada kemiskinan. } \\
\text { Faktor yang menyebabkan kemiskinan pada } \\
\text { masyarakat nelayan adalah rendanya pengetahuan serta } \\
\text { modal (Rahim et al., 2014). }\end{array}$ & $\begin{array}{l}\text { Pemberdayaan dilakukan dengan memberika modal usaha nelayan } \\
\text { tradisoinal dan usaha produktif nelayan dimana nelayan harus tau } \\
\text { bagimana meningkatkan produksi. Selain itu dengan memberikan } \\
\text { pendampingan terhadap kelompok nelayan miskin dalam hal } \\
\text { perbaikan budaya usaha mereka dan memberikan motivasi terhadap } \\
\text { keluarga dalam mengelola keuangan. Pemberdayaan masyarakat } \\
\text { melalui pengembangan ekonomi dan peningkatan kapasitas } \\
\text { masyarakat. Di samping itu kegiatan ekonomi di wilayah pesisir } \\
\text { didukung dengan mengatur sistem pasar dan mengatur pengelolaan } \\
\text { sumberdaya laut (Rahim et al., 2014). }\end{array}$ \\
\hline
\end{tabular}




\begin{tabular}{|l|c|l|l|}
\hline \multirow{2}{*}{ No } & \multirow{2}{*}{ Studi Kasus } & \multicolumn{3}{|c|}{$\begin{array}{c}\text { Identifikasi Dan Pemberdayaan Masyarakat Miskin } \\
\text { Nelayan Tradisional }\end{array}$} \\
\cline { 3 - 5 } & & \multicolumn{1}{|c|}{ Kondisi Sosial Ekonomi } & \multicolumn{1}{|c|}{ Cara Pemberdayaan } \\
\hline 6 & Pantai Selatan Jawa & $\begin{array}{l}\text { Masyarakat nelayan Laut jawa masih masih berada } \\
\text { dalam kemiskinan akibat terbatasnya kemampuan } \\
\text { nelayan. Kebijakan pemerintah yang kurag mendukung } \\
\text { nelayan tradisional serta penyediaan fasilitas yang } \\
\text { kurang memadai (Arifianto, S dan Udi, 2013). }\end{array}$ & $\begin{array}{l}\text { Pemberdayaan masyarakat nelayan di Pantai Selatan Jawa yaitu } \\
\text { dengan memberikan fasilitas dan pembelajaran tentang media } \\
\text { komunikasi dan Teknologi Sistem Komunikasi seperti media tatap } \\
\text { muka, handy talky, telephone seluler, radio, televisi, dan GPS. } \\
\text { Media tatap muka yang rutin digunakan untuk membahas masalah- } \\
\text { masalah yang terkait dengan nelayan (Arifianto, S dan Udi, 2013). }\end{array}$ \\
\hline
\end{tabular}




\section{Kesimpulan dan saran}

\section{a. Kesimpulan}

Kemiskinan yang dialami nelayan tradisional disebabkan dua faktor. Faktor internal seperti adanya keterbatasan dibidang pendidikan, kurangnya sarana teknologi, dan keterbatasan modal. Faktor eksternal seperti terbatasnya potensi sumber daya laut yang bisa dimanfaatkan nelayan, persaingan yang intensif, dan mekanisme pasar. Akibat kemiskinan yang melanda nelayan tradisional berpengaruh pada lingkungan tempat mereka tinggal. Kualiatas lingkungan yang semakin memburuk karena tidak mampu memperbaiki dan menjaganya. Permukiman di wilayah pesisir yang terkesan kumuh disebabkan masyarakat tidak memiliki biaya untuk memperbaikinya. Dari pembahasan studi kasus strategi pemberdayaan yang diterapkan di antaranya dengan menguatkan sumberdaya manusia seperti memberikan pelatihan ketrampilan cara pengolahan hasil tangkap nelayan, cara perbaikan mesin, cara menanggkap hasil laut yang menjaga kelesatarian. Kedua, yaitu dengan memberikan teknologi yang lebih canggih, kemudahan akses modal, dan membangun sarana dan prasarana di sektor perikanan dan kelautan. Ketiga, yaitu dengan membentuk serta menguatkan organisasi kelompok nelayan lokal. Dengan adanya hal tersebut bisa menjadi media untuk bertukar ide dan saling membantu menyelesaikan masalah. Dengan penerapan strategi di atas akan mengurangi jumlah kemiskinan nelayan tradisional.

\section{b. Saran}

1. Masyarakat perlu meningkatkan kesadaran akan pentingnya kelestarian lingkungan, misal tidak melakukan penangkapan ikan dengan alat yang merusak lingkungan,

2. Pemerintah agar lebih memberdayakan nelayan tradisional dengan modernisasi peralatan tangkap dan pengembangan pengolahan ikan,

3. Intasis pemerintah dalam bidang perikanan dan dibidang sosial ekonomi masyarakat nelayan perlu melakukan pembinaan secara berkelanjutan agar tidak terjadi tumpang tindih dan sasaran untuk meningkatkan kesejahteraan para 


\section{DAFTAR PUSTAKA}

Arifianto, S dan Udi, R. (2013). Pemberdayaan Nelayan Tradisional Melalui Media Komunikasi dan TIK di Pantai Selatan Jawa. Jurnal Masyarakat Telematika Dan Informasi, 4, 13-26. Https://mti.kominfo.go.id/index.php/mti/article/view/46

Dewi, T. K., Agustar, A., \& Mahdi, M. (2019). Pelaksanaan Program Gerakan Pensejahteraan Ekonomi Masyarakat Pesisir Dan Dampaknya Di Kelurahan Pasie Nan Tigo, Kota Padang. Jppuma Jurnal Ilmu Pemerintahan Dan Sosial Politik Universitas Medan Area, 7(1), 40. Https://Doi.Org/10.31289/Jppuma.V7i1.2139

Gai, A. M. (2020). Konsep Pemberdayaan Nelayan Pesisir Kota Surabaya Sebagai Bentuk Adaptasi Perubahan Iklim Berbasis Sustainable Livelihood, 5(1). Http://journal.ummat.ac.id/index.php/JPE/article/view/2153

Ginting, B. (2018). Model Pemberdayaan Nelayan Tradisional: Analisis Kemiskinan Nelayan Tradisional Desa Percut Kecamatan Percut Sei Tuan Kabupaten Deli Serdang Sumatera Utara. Http://repositori.usu.ac.id/handle/123456789/5080

Goso, G., \& Anwar, S. M. (2017). Kemiskinan Nelayan Tradisional Serta Dampaknya Terhadap Perkembangan Kumuh. Jurnal Manajemen Stie Muhammadiyah Palopo, 3(1), 25-37. Https://Doi.Org/10.35906/Jm001.V3i1.201

Hariyanto, S. (2014). Analisis Pemberdayaan Masyarakat Nelayan Di Pantai Prigi Kecamatan Watulimo Kabupaten Trenggalek. Jurnal Bonorowo, 2(1), 55-70. http://jurnalunita.org/index.php/bonorowo/article/view/31

Hidayat, M. (2018). Problematika Internal Nelayan Tradisional Kota Padang: Studi Faktor-

Faktor Sosial Budaya Penyebab Kemiskinan. Socius, 4(1), 31. Https://Doi.Org/10.24036/Scs.V4i1.15

Hodijah, S. (2018). Kemiskinan Dan Kondisi Pemukiman Nelayan Tradisional ( Studi Di Kelurahan Kampung Nelayan Kecamatan Tungkal Ilir Kabupaten Tanjung Jabung Barat ), 13(2), 55-64. Https://online-journal.unja.ac.id/paradigma/article/view/6747

Kadriani, L. H. (2017). Persepsi Masyarakat Nelayan Tentang Pentingnya Pendidikan Formal Di Desa Jawi-Jawi Kecamatan Bungku Selatan Kabupaten Morowali. Jurnal Penilitian Pendidikan Geografi, 47(3), 209-222. https://doi.org/10.1360/N972016-00877

Kandati, F., Mantiri, M., \& Moninjta, D. (2019). Pemberdayaan Masyarakat Nelayan Di Kecamatan Siau Barat Selatan Kampung Batusenggo (Suatu Studi Pada Dinas Peikanan, Kabupaten Kepulauan Siau Barat Tagulandang), 2(2), 1-8. Https://ejournal.unsrat.ac.id/index.php/jurnaleksekutif/article/view/23888 
Rahim, M., Tahir, M., \& Rumbia, W. A. (2014). Model Pemberdayaan Masyarakat di Wilayah Pesisir dalam Menaggulangi Kemiskinan di Kabupaten Buton, Sulawesi Tenggara. 15, 23-33. Https://journal.binus.ac.id/index.php/winners/article/view/633

Rahman, B., \& Selviyanti, E. (2018). Studi Literatur: Peran Stratifikasi Sosial Masyarakat Dalam Pembentukan Pola Permukiman. Planologi, 15(2), 195-215. Https://scholar.google.co.id/scholar?hl=id\&as_sdt=0\%2C5\&q=Studi+Literatur\%E2\%80 $\%$ AF\%3A+Peran+Stratifikasi+Sosial+Masyarakat+Dalam+Pembentukan+Pola+Permuk iman\&btnG=

Rahman, Z. (2019). Perlindungan Dan Pemberdayaan Nelayan. Jurnal Rechts Vinding Media Pembinaan Hukum dan Nasional, 1-5. Https://rechtsvinding.bphn.go.id/jurnal_online

Retnowati, E. (2011). Nelayan Indonesia Dalam Pusaran Kemiskinan Struktural (Perspektif $\begin{array}{llllll}\text { Sosial, Ekonomi Dan } & \text { Hukum). }\end{array}$ Https://doi.org/10.30742/perspektif.v16i3.79

Riza, Indra, \& Nasaruddin. (2016). Kondisi Sosial Ekonomi Nelayan Tradisional Di Kecamatan Mesjid Raya Aceh Besar Pasca Bencana Tsunami 2004 ( Studi Kasus Pemukiman Lamnga ). Jurnal Ilmu Kebencanaan, 3(1), 1-6. Http://www.jurnal.unsyiah.ac.id/JIKA/article/view/11748

Santosa, A. W. B., Iqbal, M., Mulyatno, I. pujo, Sisworo, S., Budiarto, U., \& Rindo, G. (2019). Pemberdayaan nelayan tangkap tradisional melalui penggunaan alat bantu pengumpul ikan ramah lingkungan. Jurnal Pasopati; Pengabdian Dan Inovasi Pengembangan Teknologi, 1(1), 34-40. Http://ejournal3.undip.ac.id/index.php/pasopati Vibriyanti, D. (2014). Kondisi sosial ekonomi nelayan tangkap Kota Tegal Jawa Tengah. Jurnal Kependudukan Indonesia, 9(1), 45-58. Http://ejurnal.kependudukan.lipi.go.id 